\title{
Atrial Septal Aneurysm and Intermittent Atrio -Ventricular Block: A Case Report and Literature Review
}

\section{Isaac Kofi Owusu ${ }^{1 *}$ | Yaw Amo Wiafe ${ }^{2}$}

\section{*Correspondence: Isaac Kofi Owusu}

Address: ${ }^{1}$ Department of Medicine, School of Medicine and Dentistry, College of Health Sciences, Kwame Nkrumah University of Science and Technology, Kumasi, Ghana; ${ }^{2}$ Department of Medical Diagnostics, College of Health Sciences, Kwame Nkrumah University of Science and Technology, Kumasi, Ghana

e-mail $\bowtie$ : ikeowusu@yahoo.com

Received: 05 February 2021; Accepted: 09 February 2021

Copyright: (C) 2021 Owusu IK. This is an open-access article distributed under the terms of the Creative Commons Attribution License, which permits unrestricted use, distribution, and reproduction in any medium, provided that the original work is properly cited.

\section{ABSTRACT}

Atrial Septal Aneurysm (ASA) can be congenital or acquired, and rarely reported in sub-Saharan African population. A number of studies have reported an association between ASA and cardiac arrhythmias; few studies have reported on association of ASA and cardiac conduction abnormalities. We report a case of ASA and intermittent atrio-ventricular (AV) block were detected on echocardiography and 24-hour ambulatory electrocardiography in a 65-year-old woman who presented with recurrent palpitations.

This case report shows that ASA may not be as rare in sub-Saharan African populations as it is thought. More echocardiographic studies on ASA are needed to understand the prevalence and the impact of ASA in these populations.

Keywords: Atrial Septal Aneurysm, Conduction Disorder, Atrioventricular Block, Ghana

\section{Introduction}

Atrial Septal Aneurysm (ASA) refers to a localized bulging of the atrial septum by $>10 \mathrm{~mm}$ excursion of the fossa ovalis into the right or left atrium of the heart, or a combined total excursion to the right and left by $\geq 15 \mathrm{~mm}$ (Silvestry et al., 2015). ASA may be congenital or acquired. The wider availability of echocardiography in recent times has shown that ASA is not as rare as initially presented.

According to several studies using trans-oesophageal echocardiography, the prevalence of ASA ranges between 2\% and 10\% (Olivares-Reyes et al., 1997; Mügge et al., 1995). However, data on ASA in African populations rarely exist in medical literature, perhaps due to limited access to echocardiography in most African settings (Huson et al., 2019).

Many studies have established ASA as a risk factor for thromboembolic events (Agmon et al., 
1999). Other types of cardiac abnormalities frequently associated with ASA are atrial septal defects (ASDs) and patent foramen ovale (PFO) as well as mitral valve prolapse and atrial arrhythmias (Mas et al., 2001; Janion and Kurzawski, 2007; Iliceto et al., 1984; De Ridder et al., 2003). Patients with ASA in association with ASD or PFO tend to have a high risk of thromboembolic disease (Mas et al., 2001; Janion and Kurzawski, 2007).

There are many evidences associating ASA and cardiac impulse conduction disorder (Bakalli et al., 2008; Bakalli et al., 2011). Several reports have shown possible association of right bundle branch block (RBBB) and ASA (Bakalli et al., 2008; Bakalli et al., 2011). But few publications have reported on the association of ASA and atrio-ventricular (AV) block (Odetunde et al., 2015).

We report a case of ASA with intermittent atrio-ventricular (AV) block presenting to a specialist cardiac clinic.

\section{Case Presentation}

A 65-year old woman was referred to the Precise Specialist Clinic, Kumasi, Ghana for cardiac evaluation, in May 2020; on account of six (6) months history of recurrent palpitation. She had no history of hypertension, diabetes mellitus or any other chronic medical condition. She had no history of alcohol intake or cigarette smoking. She was not on any regular medications.

Physical examination showed a well-looking elderly woman, afebrile, not dyspnoeic at rest and she had no pedal oedema. Blood pressure was 132/82 mmHg; pulse rate was 73 beats per minute, regular with good volume. Apex beat was located at the 5th left intercostal space in the mid-clavicular line, heart sounds 1 and 2 were normal and no additional heart sound or murmur was heard. Jugular venous pressure was found to be normal. Examination of the other systems was also normal.

A resting 12-lead electrocardiography was essentially normal with a heart rate of 68 beats per minute and sinus rhythm.

24-hour ambulatory electrocardiography (HOLTER) using NORAV HOLTER system showed (Fig. 1):

- A maximum, minimum and average heart rates of 95, 61, and 41 beats per minute respectively

- A maximum R-R interval of $3136 \mathrm{~ms}$

- Intermittent atrio-ventricular blocks

- $\quad$ Few episodes of monomorphic ventricular premature beats

Trans- thoracic echocardiography was performed in the left lateral decubitus position; using GE Vivid S5 ultrasound machine equipped with $3.5 \mathrm{MHz}$ sector probe. Echocardiography showed (Fig. 2): 
- Atrial septal aneurysm with aneurysmal bulging of the atrial septum into the right atrium.

- Normal left ventricular dimensions and function

- Normal right ventricular dimensions and function

- $\quad$ Slightly calcified trileaflet aortic valves with mild aortic regurgitation and no aortic stenosis

Diagnoses of atrial septal aneurysm and intermittent atrio-ventricular (AV) block were made.

The patient was referred to the teaching hospital for further cardiac evaluation and management.

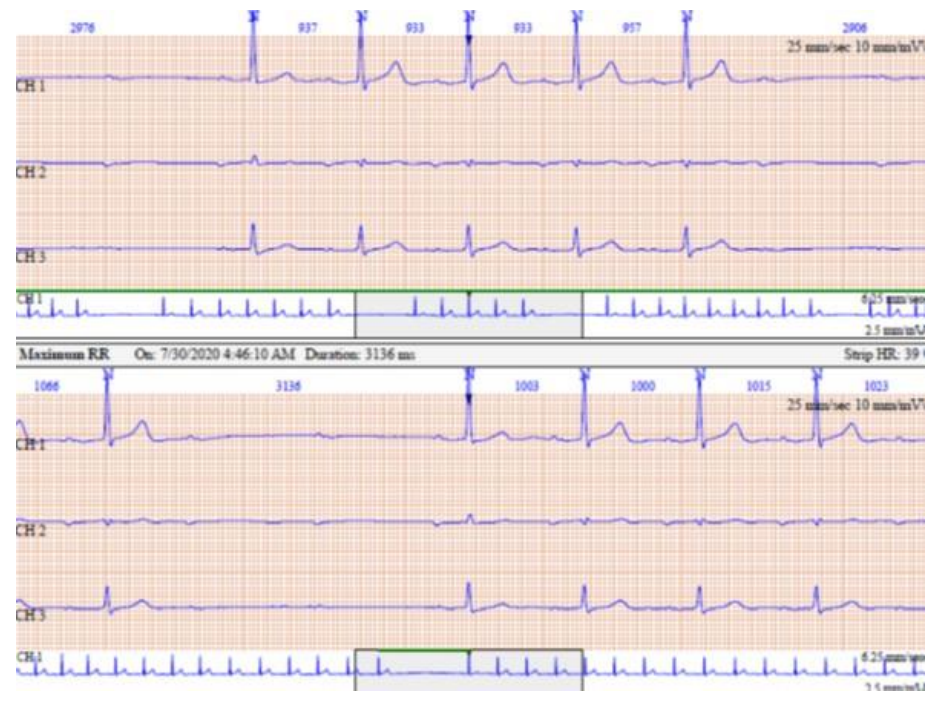

Figure 1: Ambulatory ECG recordings showing intermittent atrio-ventricular blocks, a maximum R-R interval of 3136 ms and an episode of ventricular premature beat

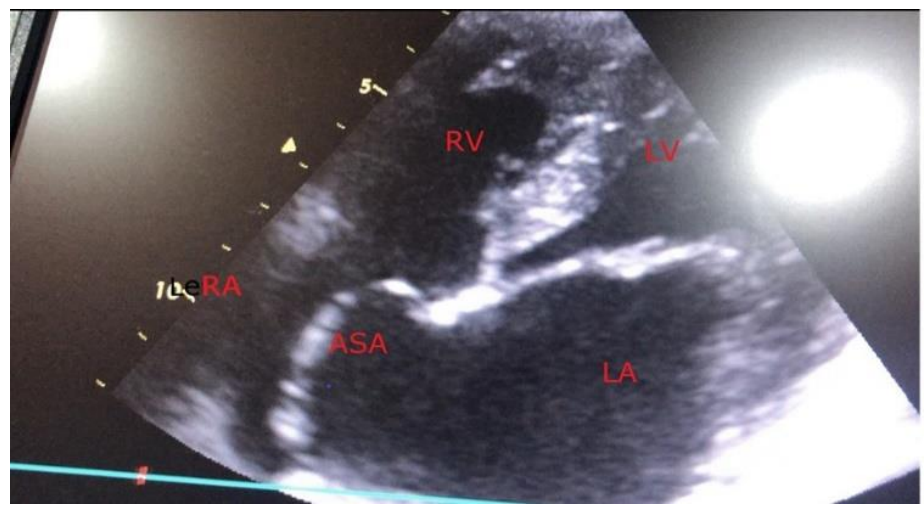

RA-Right atrium, LA-Left atrium, ASA-Atrial Septal Aneurysm, LV- Left Ventricle, RV- Right Ventricle

Figure 2: Apical 4 chamber echocardiographic view showing aneurysmal bulging of the atrial septum into the right atrium

\section{Discussion and Literature Review}

In the developed world ASA is not as rare as initially presented because of wider availability of echocardiography (Olivares-Reyes et al., 1997; Mugge et al., 1995); several studies have shown a prevalence ranging from $2 \%$ to $10 \%$. Data on ASA in sub-Saharan African population is rarely available. 
This is due to the limited access to echocardiography in these resource poor countries (Huson et al., 2019). There is generally a limited access to trans-thoracic echocardiography in many sub-Saharan African countries; and trans-oesophageal echocardiography is not available in most of these countries.

ASA has been shown to be associated with both cardiac and non-cardiac abnormalities. Cardiac abnormalities which are commonly associated with ASA include supraventricular tachyarrhythmias, atrioventricular valve prolapse, systolic clicks, atrial septal defects, systemic and pulmonary embolism (Sahn et al., 1978; Gondi and Nanda, 1981; Alexander et al., 1981; Reder et al., 1981; Ong et al., 1982). The association of ASA and cardiac impulse conduction disorder such as right bundle branch block, sinus node dysfunction and AV node dysfunction has also been shown (Bakalli et al., 2008; Bakalli et al., 2011; Odetunde et al., 2015). In fact, Odetunde, et al. reported in Nigeria a case of ASA in a new born presenting with a congenital AV block (Odetunde et al., 2015).

A number of other studies have reported association of cardiac arrhythmias and ASA. Schneider, et al. (1999) reported 40\% prevalence of arrhythmias in a population of ASA cases. Longhini, et al. (1985) also reported 57\% prevalence of arrhythmia in ASA patients, and Morelli, et al. (1995) reported $45 \%$ prevalence. Comparing ASA patients with a control group, Morelli, et al. (1995) further noted that arrhythmias were more prevalent in ASA patients than the control group. This was further confirmed by Device, et al. (2010) who reported 43.9\% prevalence of arrythmias in ASA patients with the control group recording only $8.1 \%$ cases of arrhythmia. Studies conducted by Miga, et al. (1996) and Ozem, et al. (2007) also noted that, not only were arrhythmias prevalent in ASA cases but there was also a significant statistical correlation between arrythmias and ASA. However, the arrhythmias reported by these studies were mainly tachyarrhythmias but not bradarrhythmias.

This patient had palpitations just like most ASA cases of her age, but the only difference is that she had intermittent AV block, a conduction abnormality. AV blocks are conduction abnormality which are characterized by atrio-ventricular conduction delays or a complete block of impulses from the atria into the ventricles. The commonest underlying condition in many cases of AV block is ischaemic heart disease (Vogler et al., 2012). Other underlying common conditions in patients with AV block include cardiomyopathies, myocarditis, congenital heart diseases, familial disorders and medications.

The link between AV block and ASA is still unclear, although the perception about ASA and arrhythmias in general has been linked to the possible changes in electrophysiological dynamics that may occur in the atrial myocardium (Deveci et al., 2010). The AV node is the sole connection between the atria and the ventricles. Impulses from the atria to the ventricles are modulated by the AV node which functions by delaying and limiting the number of atrial impulses reaching the ventricle. In ASA 
patients, the bulging septal shift may be a move towards a low-pressure side due to raised inter-atrial pressure gradients (Mügge et al., 1995) which can interfere with electrophysiological dynamics. However, patients with congenital forms of ASA tend to have normal atrial pressures (Mügge et al., 1995).

\section{Conclusion}

In conclusion, ASA may not be as rare in sub-Saharan African populations as it is thought. More echocardiographic studies on ASA are needed to understand the prevalence and the impact of ASA in these populations.

\section{Acknowledgements}

The authors would like to express their sincere gratitude to the management and staff of the Precise Specialist Clinic, Kumasi, Ghana for their support.

\section{References}

Agmon Y, Khandheria BK, Meissner I, Gentile F, Whisnant JP, Sicks JD, O’Fallon WM, Covalt JL, Wiebers DO, Seward JB. "Frequency of atrial septal aneurysms in patients with cerebral ischemic events," Circulation 1999; 99: 1942-1944.

Alexander MD, Bloom KR, Hart p, D'Silva F, Murgo J. Atrial septal aneurysm: a cause for midsystolic click; report of a case and review of the literature. Circulation 1981; 63: 1186-1188.

Bakalli A, Kamberi L, Pllana E, Gashi A. Atrial septal aneurysm association with additional cardiovascular comorbidities in two middle age female patients with ECG signs of right bundle branch block: Two case reports. Case J 2008; 1: 51.

Bakalli A, Pllana E, Kocinaj D, Bekteshi T, Dragusha G, Gashi M, Musliu N, Gashi Z. Association of interatrial septal abnormalities with cardiac impulse conduction disorder in adult patients: experience from a tertiary center in Kosovo. Heart Int 2011; 6: 11-1 5 .

Bostan OM, Cil E, Ercan I. The prospective follow- up of the natural course of interatrial communications diagnosed in 847 newborns. Eur Heart J 2007; 28: 2001-2005.

De Ridder S, Cramer MJ, Ernst JM, Jaarsma W. "Giant multiperforated atrial septal aneurysm in a patient with paroxysmal atrial fibrillation," Eur J Echocardiogr 2003; 4: 154-156.

Deveci OS, Aytemir K, Okutucu S, Tulumen E, Aksoy H, Kaya EB, Evranos B, Kabakci G, Tokgozoglu L, Oto A, Ozkutlu H. Evaluation of the relationship between atrial septal aneurysm and cardiac arrhythmias via P-wave dispersion and signalaveraged P-wave duration. Ann Noninvasive Electrocardiol 2010; 15: 157-164.

Gondi B and Nanda Ne. Two-dimensional echocardiographic features of atrial septal aneurysm. Circulation 1981; 63: 452-457.

Huson MA, Kaminstein D, Kahn D, Belard S, Ganesh P, Kandoole-Kabwere V, Wallrauch C, Phiri S, Kreuels B, Heller T. Cardiac ultrasound in resource-limited settings (CURLS): towards a wider use of basic echo applications in Africa. Ultrasound J 2019; 11: 34. 
Iliceto S, Papa A, Sorino M, Rizzon P. "Combined atrial septal aneurysm and mitral valve prolapse: detection by twodimensional echocardiography,” Am J Cardiol 1984; 54: 1151-1153.

Janion M and Kurzawski J. “Atrial fibrillation in patients with atrial septal aneurysm,” Cardiol J 2007; 14: 580-584.

Longhini C, Brunazzi MC, Musacci G, Caneva M, Bandello A, Bolomini L, Barbiero M, Toselli T, Barbaresi F. Atrial septal aneurysm: echopolycardiographic study. Am J Cardiol 1985; 56: 653-656.

Mas JL, Arquizan C, Lamy C, Zuber M, Cabanes L, Derumeaux G, Coste J. "Recurrent cerebrovascular events associated with patent foramen ovale, atrial septal aneurysm, or both,” N Engl J Med 2001; 345: 1740-1746. 778.

Miga DE, Case CL, Gillette PC. Interatrial septal aneurysms and atrial arrhythmias in infants. Am Heart J 1996; 132: 776-

Morelli S, Voci P, Morabito G, Sgreccia A, De Marzio P, Marzano F, Giordano M. Atrial septal aneurysm and cardiac arrhythmias. Int J Cardiol 1995; 49: 257-265.

Mügge A, Daniel WG, Angermann C, Spes C, Khandheria BK, Kronzon I, Freedberg RS, Keren A, Dennig K, Engberding R, Sutherland GR. "Septal aneurysm in adult patients. A multicenter study using transthoracic and transesophageal echocardiography," Circulation 1995; 91: 2785-2792.

Odetunde OI, Ekwochi U, Chinawa JM, Ejim EC, Ezugwu FO. Conducting defect with atrial septal aneurysm in a preterm neonate: A case report from resource limited setting. Niger J Paed 2015; 42: 64-67.

Olivares-Reyes A, Chan S, Lazar EJ, Bandlamudi K, Narla V, Ong K. "Atrial septal aneurysm: a new classification in two hundred five adults," J Am Soc Echocardiogr 1997; 6: 644-656.

Ong LS, Nanda NC. Fa1koff MD. Barold SS. Interatrial septal aneurysm, systolic click and atrial tachyarrhythmia-a new syndrome'. Ultrasound Med BioI 1982; 8: 691-693.

Reder RF, Yeh HC, Steinfeld L. Aneurysm of the interatrial septum causing pulmonary venous obstruction in an infant with tricuspid atresia. Am Heart J 1981; 102: 786-789.

Sahn OJ, Allen HD, Anderson R, Goldberg SJ. Echocardiographic diagnosis of atrial septal aneurysm in an infant with hypoplastic right heart syndrome. Chest 1978; 73: 227-230.

Schneider, B Hofmann, T Meinertz T. Is there an association of atrial septal aneurysm with arrhythmias? Cardiology 1999; 91: 87-91.

Silvestry FE, Cohen MS, Armsby LB, Burkule NJ, Fleishman CE, Hijazi ZM, Lang RM, Rome JJ, Wang Y. Guidelines for the echocardiographic assessment of atrial septal defect and patent foramen ovale: from the American Society of Echocardiography and Society for Cardiac Angiography and Interventions. J Am Soc Echocardiogr 2015; 28: 910-958.

Vogler J, Breithardt G, Eckardt L. Bradyarrhythmias and conduction blocks. Revista Española de Cardiología (English Edition). 2012; 65: 656-667. 